\title{
Abnormal Distribution of Aquaporin-5 Water Channel Protein in Salivary Glands from Sjögren's Syndrome Patients
}

\author{
Serge Steinfeld, Elie Cogan, Landon S. King, Peter Agre, Robert Kiss, and \\ Christine Delporte
}

Divisions of Rheumatology (SS) and Internal Medicine (EC), Erasme University Hospital, and Laboratories of Histopathology (RK) and Biochemistry (CD), Université Libre de Bruxelles, Brussels, Belgium; and Departments of Biological Chemistry and Medicine (LSK, PA), The Johns Hopkins University School of Medicine, Baltimore, Maryland

SUMMARY: Patients with Sjögren's syndrome (SS) suffer from deficient secretion of saliva due to an autoimmune destruction of salivary glands, however, glandular dysfunction also occurs without destruction. Based upon its abnormal distribution in SS salivary glands, a potential role for the water channel protein aquaporin-5 (AQP5) is proposed in the pathogenesis of SS. The immunohistochemical distribution of AQP5 was compared in minor salivary gland biopsies obtained from women after informed consent: primary SS $(53.2 \pm 14$ years old, $n=10)$, healthy volunteers $(46.2 \pm 17$ years old, $n=10)$, patients with sarcoidosis (37 and 48 years old), and patients with non-specific sialoadenitis (54 and 61 years old). Biopsies from normal subjects revealed AQP5 primarily at the apical membrane of the salivary gland acinus. In contrast, biopsies from SS patients revealed AQP5 primarily at the basal membranes of the acinus. The AQP5 distribution in biopsies from patients with other dry mouth disorders, such as non-specific sialoadenitis or sarcoidosis, was similar to biopsies from control subjects. Computer-assisted microscopy was performed to quantitatively evaluate AQP5 distribution in the immunoreactive acini of both SS and control subjects. Biopsies from SS patients had higher labeling indices (percentage of acinus area immunoreactive for AQP5) at the basal membrane when compared with biopsies from control subjects. In contrast, biopsies of SS patients exhibited lower labeling indices at the apical membrane when compared with biopsies from control subjects. To verify the specificity of the AQP5 antibody, Western blot analysis was performed on membranes from Xenopus oocytes injected with AQP5 CRNA or on membranes from minor salivary glands of control subjects and SS patients. In each case, the immunoblots had a $27 \mathrm{kd}$ band, corresponding to the expected molecular weight of AQP5. Abnormal distribution of AQP5 in salivary gland acini is likely to contribute to the deficiency of fluid secretion, which is a defining feature of Sjögren's syndrome. (Lab Invest 2001, 81:143-148).

\begin{abstract}
Sögren's syndrome (SS) is a common inflamma$\circlearrowleft$ tory disease characterized by lymphocytic infiltration of salivary and lacrimal glands leading to glandular hypofunction and dry mouth and eyes (Thomas et al, 1998). Salivary gland biopsies show lymphocytic infiltrates with a maximal $50 \%$ decrease in acini number (Andoth et al, 1993), and metalloproteinases have been implicated in acinar destruction (Azuma et al, 1997). However, in addition to loss of gland elements, gland dysfunction plays an important role in the clinical expression of the disease (Thomas et al, 1998). Several factors may contribute to impaired salivary flow, including proinflammatory cytokines, such as IL-1 and TNF- $\alpha$, that can inhibit both basal and stimulated secretion (Fox, 1997; Soliven and Wang,
\end{abstract}

Received August 7, 2000.

This work was supported by a grant from the National Bank of Belgium (BNB), grant 3.4502.99 from the Fund for Medical Scientific Research (Belgium), and grants from the National Institutes of Health (USA). Address reprint requests to: Dr. Christine Delporte, Laboratory of Biochemistry, CP 611, Université Libre de Bruxelles, Route de Lennik 808, B-1070 Brussels,Belgium.E-mail: cdelport@med.ulb.ac.be
1995). Decreased protein kinase C levels in salivary gland acinar cells of SS patients (Tornwall et al, 1997), along with the presence of antibodies against muscarinic M3 receptor in primary SS patients could prevent normal gland responses to neuronal stimulation (Bacman et al, 1996).

In a normal salivary gland, the acini secrete a primary isotonic fluid from which considerable $\mathrm{NaCl}$ is resorbed during the passage through the ducts. Ductal cells possess a sodium channel (Cook et al, 1994; Moran et al, 1995), a chloride channel (Cook et al, 1994; He et al, 1997), and a sodium-proton exchanger (Cook et al, 1994; He et al, 1997), which are likely to be involved in $\mathrm{NaCl}$ reabsorption, as well as a potassiumproton exchanger that may mediate potassium and bicarbonate secretion (Cook et al, 1994; Knauf et al, 1982).

Recent discovery of a family of water-specific membrane channel proteins, the aquaporins, provided insight into the molecular mechanism of membrane water permeability in a variety of tissues (Agre et al, 1995; Borgnia et al, 1999; King and Agre 1996; Knepper, 1994; Verkman et al, 1996). Aquaporin-1 (AQP1) 
provides the molecular pathway for water reabsorption in the renal proximal tubule and vasa recta (Nielsen et al, 1993), participates in lung water homeostasis (King and Agre, 1996), and in the secretion of cerebrospinal fluid, aqueous humor (Nielsen et al, 1993; Stamer et al, 1994), and bile (Roberts et al, 1994). Aquaporin-5 (AQP5) was cloned from rat submandibular glands and is also present in the lacrimal gland and lung, suggesting roles in generation of saliva, tears, and pulmonary secretions (Raina et al, 1995). Among the aquaporins identified to date, only AQP1 and AQP5 have been immunohistochemically localized to rat salivary glands. AQP1 is present in capillaries and venules adjacent to the gland epithelium (Delporte et al, 1997; Li et al, 1992; Nielsen et al, 1993). AQP5 is present in the apical membrane of acinar cells (Agre et al, 1995; He et al, 1997; Nielsen et al, 1997) and the proximal segment of intercalated ducts (He et al, 1997; Matsuzaki et al, 1999; Nielsen et al, 1997), predicting participation in water transport across the glandular epithelium. Recently, Ma et al (1999) reported that transgenic mice lacking AQP5 exhibit decreased saliva secretion, confirming the physiologic relevance of AQP5 in salivary gland function.

The aims of this study were to characterize the cellular distribution of human aquaporin-5 (hAQP5) in minor salivary glands (MSG) from SS patients and normal subjects and to investigate potential differences in the pattern of expression.

\section{Results}

\section{hAQP5 Antibodies}

The C-terminus of hAQP5 differs from its rat homolog at 6 of 22 residues (Lee et al, 1996). Although an antibody prepared to rat AQP5 reacts well with rat tissues (Delporte et al, 1996; King et al, 1997), the reagent produces limited cross-reactivity with human tissues. Therefore, an antibody to a synthetic peptide corresponding to the C-terminus of hAQP5 was prepared. An immunoblot of membranes from uninjected oocytes and oocytes injected with hAQP5 cRNA was probed with the antibody (Fig. 1). A single band at 27

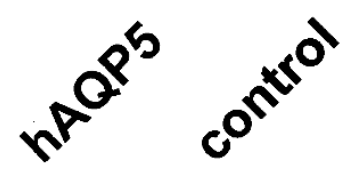

\section{$27 \mathrm{kDa}-$}

Figure 1.

Specificity and reactivity of human aquaporin-5 (hAQP5) antibodies. Immunoblot of total membranes from $X$. laevis oocytes injected with water (control) or cRNA encoding hAQP5 (15 $\mu \mathrm{g}$ of protein per lane) probed with anti-hAQP5.
kDa was evident in membranes of hAQP5 oocytes probed with the new antibody; no labeling was detected in water-injected control oocytes.

Western blot analysis of 17,000 g membranes from MSG of control subjects and SS patients probed with the hAQP5 antibody also demonstrated a $27 \mathrm{kDa}$ band (Fig. 2).

\section{Immunohistochemical Localization of hAQP5 in MSG from Control Subjects and SS Patients}

In MSG biopsies from normal subjects, hAQP5 was detected by immunohistochemistry primarily at the apical membrane of the acinar cells (Fig. 3, A and C). In contrast, MSG biopsies from SS patients revealed hAQP5 expression primarily at the basal membrane of the acinar cells (Fig. 3, B and D). The hAQP5 distribution in MSG biopsies from patients with other dry mouth disorders, such as non-specific sialoadenitis (Fig. 3E) or sarcoidosis (data not shown), was similar to MSG biopsies from control subjects. In ductal cells of MSG biopsies from normal subjects, SS patients (Fig. 3D) and patients with non-specific sialoadenitis or sarcoidosis, hAQP5 was detected apically, basolaterally, and intracellularly.

A computer-assisted microscopy procedure was performed to quantitatively evaluate the labeling index (LI) of the immunoreactive acini (Table 1). The LI corresponds to the percentage of acinus area immunoreactive for hAQP5 in each region of the cell. MSG biopsies from SS patients exhibited higher $\mathrm{LI}$ at the basal membrane of the acinar cells (42.5 $\pm 3.7 \%)$ when compared with MSG biopsies from control subjects $(11.4 \pm 1.5 \%)$. In contrast, MSG biopsies from SS patients exhibited lower $\mathrm{LI}$ at the apical membrane of acinar cells $(68.7 \pm 4.1 \%)$ when compared with biopsies from control subjects $(94.6 \pm 1 \%)$ (Table 1$)$.

\section{Determination of Serum Immunoreactivity to hAQP5}

Protein immunoblots of membranes from hAQP5expressing oocytes were probed with serum from 10 SS patients and 5 control subjects. No antibodies directed against hAQP5 were detected in sera from patients with SS (data not shown).
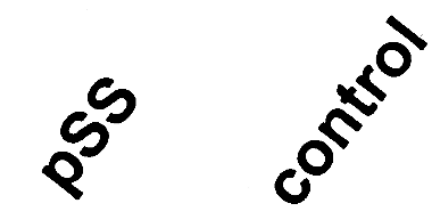

\section{$27 \mathrm{kDa}-$}

Figure 2.

hAQP5 expression in minor salivary glands (MSG) of control subjects and Sjögren's syndrome (SS) patients. Western blot analysis was performed using $10 \mu \mathrm{g}$ of $17,000 \mathrm{~g}$ membranes from MSG of control subjects or SS patients and anti-hAQP5 diluted at 1:2000. 


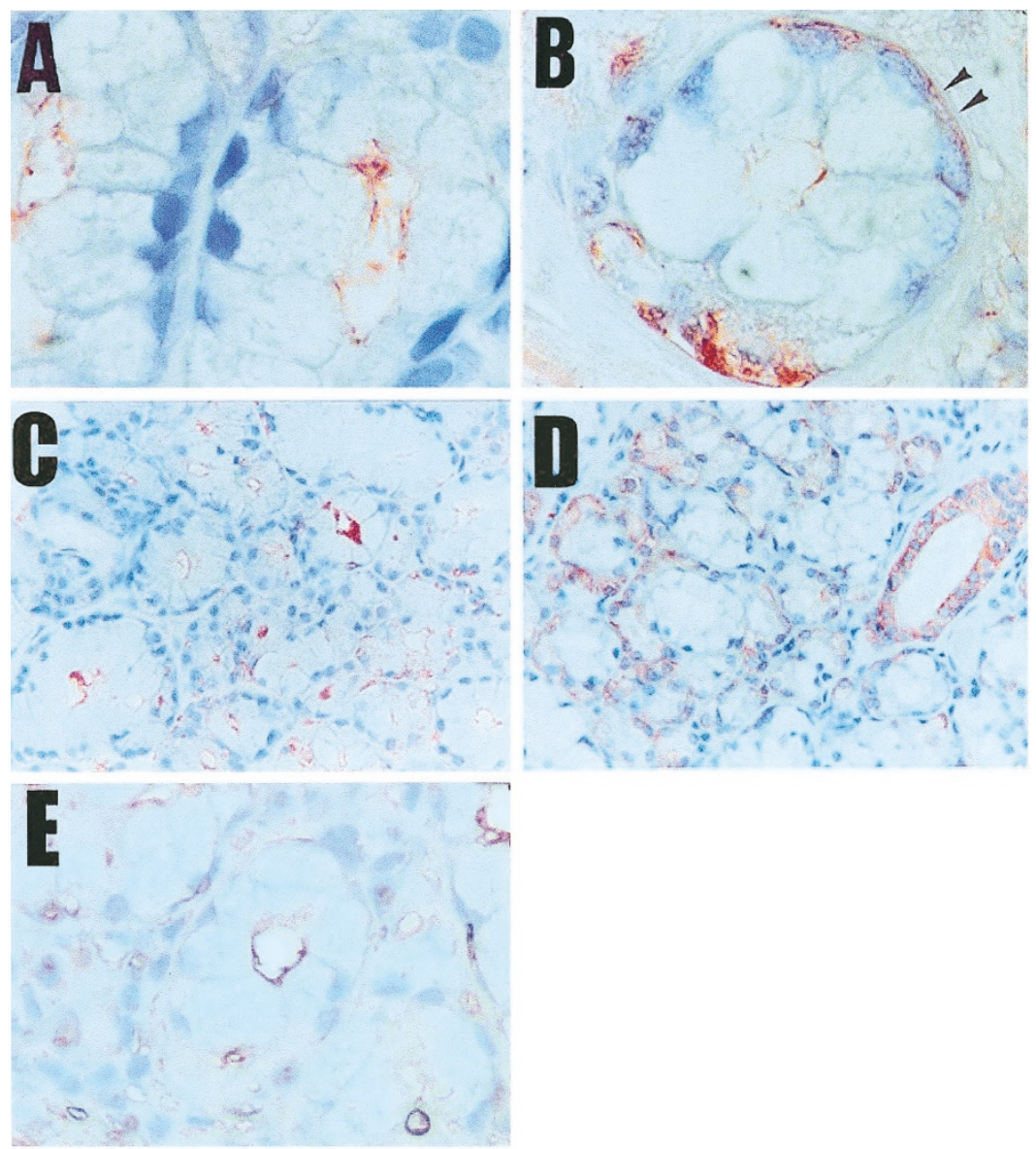

\section{Figure 3}

Immunohistochemical localization of hAQP5 in MSG. AQP5 was localized on MSG sections from a control subject (A, C), an SS patient (B, D), and a patient with nonspecific sialoadenitis $(E)(A, B$, and $E$, original magnification, $\times 40 ; C$ and D, original magnification, $\times 20$ ), using affinity-purified hAQP5 antibodies and a Histostain SP kit. The AQP5 localization was representative of immunoreactivity of MSG sections from 10 control subjects, 10 SS patients, and 2 patients with nonspecific sialoadenitis. A negative control was performed with hAQP5 antibody that had been previously incubated with the immunizing peptide (1.5 mg/ml) (data not shown)

Table 1. Quantitative Analysis of the hAQP5 Immunoreactive Acini from MSGa

\begin{tabular}{|c|c|c|}
\hline & \multicolumn{2}{|c|}{ LI (\%) } \\
\hline & Apical & Basal \\
\hline Control subjects & $94.6 \pm 1.0$ & $11.4 \pm 1.5$ \\
\hline SS patients & $68.7 \pm 4.1^{*}$ & $42.5 \pm 3.7^{*}$ \\
\hline
\end{tabular}

MSG, minor salivary glands; LI, labeling index; SS, Sjögren's syndrome.

${ }^{a}$ Quantitative analysis of the $\mathrm{LI}$ of the labeled structures was performed using a SAMBA 2005 computer-assisted microscope system (UNILOG, Grenoble, France) with a $\times 20$ (aperture, 0.50) magnification lens. LI corresponds to the percentage of acinus area stained for hAQP5. Values are expressed as the mean \pm SEM. Mann-Whitney $U$ test was used to evaluate the statistical differences.

${ }^{*} \mathrm{p}<0.01$.

\section{Discussion}

Although the biological mechanisms that lead to sicca symptoms in SS are poorly understood, it is increasingly evident that dryness of the eyes and mouth do not result solely from gland destruction. Cytokines, autoantibodies, or soluble factors may also contribute to gland dysfunction (Humphreys-Beher and Peck, 1999). Based upon its distribution, a potential role for the water channel protein AQP5 was evaluated in the pathogenesis of SS in this study.

The subcellular localization of AQP5 in rat salivary glands has been demonstrated (He et al, 1997; Nielsen et al, 1997). However, to our knowledge, the present study provides the first description of the localization of AQP5 in human MSG, and indicates a distinct distribution pattern in MSG from SS patients. hAQP5 immunoreactivity was predominantly localized to the apical membrane of acinar cells from control subjects. In contrast, hAQP5 expression was more prominent at the basal membrane of acinar cells in MSG biopsies from SS patients. A quantitative analysis using a computer-assisted microscope system further confirmed that the $\mathrm{LI}$ of the immunoreactive acini was lower at the apical membrane and higher at the basal membrane of acinar cells in MSG from SS patients as compared with normal subjects. In MSG, the abnormal distribution of AQP5 observed in SS patients was specific to SS, because other dry mouth pathologies such as non-specific sialoadenitis and sarcoidosis had AQP5 distributions that were similar to control subjects. Also, Western blot analysis on 17,000 g membranes from MSG of control subjects and SS 
patients, performed to verify the specificity of the hAQP5 antibody, showed a $27 \mathrm{kDa}$ band, corresponding to the expected molecular weight of AQP5.

The predominance of AQP5 immunoreactivity at the basal membrane of acinar cells from SS patients suggests a defect in AQP5 routing. Similar observations of altered protein trafficking in SS patients were shown for the $\mathrm{Na}^{+}$-independent chloride-bicarbonate anion exchanger (Vazquez et al, 1995). However, autoantibodies to AQP5 could not account for misrouting, because no hAQP5 antibodies were detected in sera from 10 patients with SS. Impaired AQP5 trafficking could be responsible for the decrease in saliva production observed in SS patients, a hypothesis supported by the recent demonstration of reduced salivary fluid secretion in AQP5 knock-out mice (Ma et al, 1999). Further studies of basic mechanisms of AQP5 trafficking may provide valuable insight into AQP5 regulation in its routing in MSG from both control subjects and SS patients. AQP5 misrouting could also be involved in dry-mouth postirradiation therapy for head and neck cancer.

Water channel gene transfer could be a potential therapeutic approach in SS patients, and in patients suffering from impaired saliva production resulting from radiation therapy for head and neck cancer (Silverman, 1992; Vissink et al, 1991). Increased fluid secretion is observed after adenoviral-mediated gene transfer of the AQP1 cDNA to irradiated rat salivary glands (Delporte et al, 1997). More recently, gene transfer to irradiated parotid glands of non-human primates was well tolerated, although its functional utility in enhancing fluid secretion was inconsistent (O'Connell et al, 1999).

In conclusion, this study provides the first description of the localization of AQP5 in human MSG, and indicates an abnormal distribution of AQP5 in MSG from SS patients, which could be responsible for a loss of saliva secretion in these patients.

\section{Material and Methods}

\section{Patients}

MSG biopsies of the lower lip were obtained from women after informed consent. Biopsies were obtained from primary SS patients (25 to 69 years old, mean: $53.2 \pm 14$ years old, $n=10$ ), healthy volunteers (22 to 68 years old, mean: $46.2 \pm 17$ years old, $\mathrm{n}=$ 10), two patients with sarcoidosis (37 and 48 years old), and two patients with nonspecific sialoadenitis (54 and 61 years old). SS patients fulfilled both the San Diego (Fox et al, 1986) and the modified European Community (Vitali et al, 1993) classification criteria for SS, and had Ro/SS-A and La/SS-B antibodies. Biopsies were evaluated for focus scores according to the method described by Greenspan et al (1974) and exhibited a focus score $>2$ per $4 \mathrm{~mm}^{2}$ area. One focus is equal to an aggregate of $\geq 50$ mononuclear cells per $4 \mathrm{~mm}^{2}$ area of salivary gland.

\section{Determination of Antinuclear Antibodies}

An indirect immunofluorescence procedure using Hep.2 cell substrates was employed to detect the presence and titer of antinuclear antibody (ANA) (Immunoconcept, Sacramento, California). Ro/SSA and $\mathrm{La} / \mathrm{SSB}$ antibodies were detected by ELISA (INOVA Diagnostics, San Diego, California).

\section{Antibodies to hAQP5}

All studies were undertaken with affinity-purified antibodies. The antibody specific for hAQP5 was prepared as described (Terris et al, 1995). A synthetic peptide corresponding to the carboxy-terminus of hAQP5 (NH2-CEPDEDWEEQREERKKTMELTTR-COOH) (Lee et al, 1996) was cross-linked to keyhole limpet hemocyanin, and was used to immunize New Zealand white rabbits (Lofstrand Laboratories, Gaithersburg, Maryland). Polyclonal anti-hAQP5 IgG was affinity-purified from serum using Sulfolink coupling gel (Pierce Chemical, Indianapolis, Indiana) conjugated with 2 to $4 \mathrm{mg}$ of the synthetic peptide.

Specificity and reactivity of the hAQP5 antibodies were determined by protein immunoblot. Briefly, $50 \mathrm{nl}$ of water or $5 \mathrm{ng}$ of hAQP5 cRNA (Lee et al, 1996) was injected into defolliculated stage $\mathrm{V}$ to $\mathrm{VI}$ Xenopus laevis oocytes as described (Preston et al, 1993). After incubating for 3 days, oocyte membranes were harvested and solubilized in $1 \%$ SDS, subjected to electrophoresis in $12 \%$ acrylamide gels, and transferred to nitrocellulose. Immunoblots were incubated with the hAQP5 antibody (1:2000 dilution), and visualized with chemiluminescence (Amersham, Braunschweig, Germany) and autoradiography. An affinity-purified polyclonal rat AQP5 antibody, prepared as described elsewhere (Delporte et al, 1996) and kindly provided by Dr. B. Baum, did not cross-react with the hAQP5 protein.

Protein immunoblots of $17,000 \mathrm{~g}$ membranes $(10 \mu \mathrm{g}$ of protein/lane) from MSG of control or SS patients were probed with the hAQP5 antibody as described above.

In an additional set of studies, protein immunoblots of membranes from control and hAQP5-expressing Xenopus oocytes were probed with serum from 10 patients with SS and 5 control patients (1:100 dilution), and visualized as described.

\section{Immunohistochemical Localization of hAQP5}

Immediately after removal, MSG tissue biopsies were fixed in $4 \%$ buffered formaldehyde, paraffinembedded, and sectioned (5 $\mu \mathrm{m}$ thick). AQP5 was localized by immunohistochemistry using hAQP5 antibodies (dilution 1:100) and a Histostain SP kit (Zymed Laboratories, San Francisco, California). As a control, MSG sections were incubated either with secondary antibody alone or with hAQP5 antibody pre-adsorbed with the immunizing peptide in 100-fold excess. 


\section{Determination of Immunoreactivity}

The $\mathrm{LI}$ corresponds to the percentage of acinus area immunoreactive for hAQP5 in each region of the cell. Quantitative analysis of the $\mathrm{LI}$ of the immunoreactive acini was performed as previously described (Camby et al, 1999; Steinfeld et al, 1999), using a SAMBA 2005 computer-assisted microscope system (UNILOG, Grenoble, France) equipped with a $20 \times$ magnification lens (aperture 0.50). On each pixel, the tissueintegrated optical density due to the hematoxylin counter-staining and the red aminoethyl carbazole chromogen were computed on 256 densitometric levels in two color channels. Immunoreactivity generated by binding of the histochemical probe was defined by the integrated optical values in excess of the mean plus two standard deviations of the corresponding negative control.

The computer-assisted microscope and related quantitative analyses were standardized as follows. A negative histological control slide (from which the primary antibody was omitted) was analyzed for each experimental condition. The software used on the computer-assisted microscope automatically subtracted the $\mathrm{LI}$ and MOD values of the negative control sample from each of the two positive samples available for each experimental condition. Specific software was included in the computer assisting the microscope to check any inherent shading in the CCD camera-based systems, the glare phenomenon, and the level of linear precision. The shading and glare were checked each week. The monitoring procedure installed on our computer-assisted microscope showed that neither shading, glare, nor linearity significantly modified our results (data not shown). Twenty acini and ten ducts were analyzed in each experimental condition.

\section{Statistical Analysis}

Laboratory data are expressed as the mean \pm SEM The Mann-Whitney $U$ test was used to evaluate the statistical differences in AQP5 expression in MSG from normal subjects and SS patients. All statistical analyses were carried out using Statistica software (Statsoft, Tulsa, Oklahoma).

\section{Acknowledgement}

The authors thank M. Stiévenart for his secretarial assistance.

\section{References}

Agre P, Brown D, and Nielsen S (1995). Aquaporin water channels: Unanswered questions and unresolved controversies. Curr Opin Cell Biol 7:472-483.

Andoth Y, Shimura S, Sawai T, Sasaki H, Takishima T, and Shirato K (1993). Morphometric analysis of secretory glands in Sjögren's syndrome. Am Rev Respir Dis 148:1358-1362.

Azuma M, Motegi K, Aota K, Hayashi Y, and Sato M (1997). Role of cytokines in the destruction of acinar structure in Sjögren's syndrome salivary glands. Lab Invest 77:269-280.
Bacman S, Sterin-Borda L, Camusso JJ, Arana R, Hubscher O, and Borda E (1996). Circulating antibodies against rat parotid gland M3 muscarinic receptors in primary Sjögren's syndrome. Clin Exp Immunol 104:454-459.

Borgnia M, Nielsen S, Engel A, and Agre P (1999). Cellular and molecular biology of the aquaporin water channels. Annu Rev Biochem 68:425-458.

Camby I, Nagy N, Lopes MB, Schafer BW, Maurage CA, Ruchoux MM, Murmann P, Pochet R, Heizmann CW, Brotchi J, Salmon I, Kiss R, and Decaestecker C (1999). Supratentorial pilocytic astrocytomas, astrocytomas, anaplastic astrocytomas and ganglioblastomas are characterized by a differential expression of S100 proteins. Brain Pathol 9:1-19.

Cook DI, Van Lennep EW, Roberts ML, and Young JA (1994). Secretion by the major salivary glands. In: Johnson LR, editor. Physiology of the gastrointestinal tract. New York: Raven, 1061-1117.

Delporte C, O'Connell BC, He X, Ambudkar IS, Agre P, and Baum BJ (1996). Adenovirus-mediated expression of aquaporin-5 in epithelial cells. J Biol Chem 271:2207022075.

Delporte C, O'Connell BC, He X, Lancaster H, O'Connell A, Agre $P$, and Baum BJ (1997). Increased fluid secretion following transfer of the aquaporin-1 cDNA to irradiated rat salivary glands. Proc Natl Acad Sci USA 94:3268-3273.

Fox RI, Robinson CA, Curd JG, Kozin F, and Howell FV (1986). Sjögren's syndrome. Proposed criteria for classification. Arthritis Rheum 29:577-585.

Fox RI (1997). Sjögren's syndrome: Controversies and progress. Clin Lab Med 17:431-434.

Greenspan JS, Daniels TE, Talal N, and Sylvester RA (1974). The histopathology of Sjögren's syndrome in labial salivary gland biopsies. Oral Surg Oral Med Oral Pathol 37:217-229.

He X, Tse C-M, Donowitz M, Alper SL, Gabriel SE, and Baum BJ (1997). Polarized distribution of key membrane transport proteins in the rat submandibular gland. Pflugers Arch 433: 260-268.

Humphreys-Beher MG and Peck AB (1999). New concepts for the development of autoimmune exocrinopathy derived from studies with the NOD mouse model. Arch Oral Biol 44(Suppl 1):S21-S25.

King LS and Agre P (1996). Pathophysiology of the aquaporin water channels. Annu Rev Physiol 58:619-648.

King LS, Nielsen S, and Agre P (1997). Aquaporins in complex tissues: I. Developmental patterns in respiratory tract and glandular tissue of rat. Am J Physiol 273:C1541-C1548.

Knauf H, Lubcke R, Kreutz W, and Sachs G (1982). Interrelationships of ion transport in rat submaxillary duct epithelium. Am J Physiol 242:F132-F139.

Knepper M (1994). The aquaporin family of molecular water channels. Proc Natl Acad Sci USA 91:6255-6258.

Lee MD, Bhakta KY, Raina S, Yonescu R, Griffin CA, Copeland NG, Gilbert DJ, Jenkins NA, Preston GM, and Agre P (1996). The human aquaporin-5 gene: Molecular characterization and chromosomal localization. J Biol Chem 271: 8599-8604.

Li J, Nielsen S, Dai Y, Lazowski KW, Christensen El, Tabak LA, and Baum BJ (1992). Examination of rat salivary glands for the presence of the aquaporin CHIP. Pflugers Arch 428:455-460. 
Ma T, Song Y, Gillespie A, Carlson EJ, Epstein CJ, and Verkman AS (1999). Defective secretion of saliva in transgenic mice lacking aquaporin-5 channels. J Biol Chem 274: 20071-20074.

Matsuzaki T, Suzuki T, Koyama H, Tanaka S, and Takata K (1999). Aquaporin-5 (AQP5), a water channel protein, in the rat salivary and lacrimal glands: Immunolocalization and effect of secretory stimulation. Cell Tissue Res 295:513-521.

Moran A, Davis VH, and Turner RJ (1995). Na+ channels in membrane vesicles from intralobular salivary ducts. Am $\mathrm{J}$ Physiol 268:C350-C355.

Nielsen S, Smith BL, Christensen El, and Agre P (1993). Distribution of the aquaporin CHIP in secretory and resorptive epithelia and capillary endothelia. Proc Natl Acad Sci USA 90:7275-7279.

Nielsen S, King LS, Christensen BM, and Agre P (1997). Aquaporins in complex tissues. II. Subcellular distribution in respiratory and glandular tissues of rat. Am J Physiol 273: C1549-C1561.

O'Connell A, Baccaglini L, Fox PC, O'Connell BC, Kenshalo D, Oweisy H, Hoque ATMS, Sun D, Hersher LL, Braddon VR, Delporte C, and Baum BJ (1999). Safety of adenovirusmediated transfer of the human aquaporin-1 cDNA to irradiated parotid glands of non-human primates. Cancer Gene Ther 6:503-513.

Preston GM, Jung JS, Guggino WB, and Agre P (1993). The mercury-sensitive residue at cysteine-189 in the CHIP28 water channel. J Biol Chem 268:17-20.

Raina S, Preston GM, Guggino WB, and Agre P (1995). Molecular cloning and characterization of an aquaporin cDNA from salivary, lacrimal, and respiratory tissues. J Biol Chem 270:1908-1912.

Roberts SK, Yano M, Ueno Y, Pham L, Alpini G, Agre P, and LaRusso NF (1994). Cholangiocytes express the aquaporin CHIP and transport water via a channel-mediated mechanism. Proc Natl Acad Sci USA 91:13009-13013.

Silverman S (1992). Precancerous lesions and oral cancer in the elderly. Clin Geriatr Med 8:529-541.

Soliven B and Wang N (1995). Tumor necrosis factor alpha regulates responses of cultures of sympathetic neurons and nonneuronal cells. J Neurochem 64:883-894.
Stamer WD, Snyder RW, Smith BL, Agre P, and Regan JW (1994). Localization of aquaporin CHIP in the human eye: Implications in the pathogenesis of glaucoma and other disorders of ocular fluid balance. Invest Ophthalmol Vis Sci 35:3867-3872.

Steinfeld S, Penaloza A, Ribaï P, Decaestecker C, Danguy A, Gabius HJ, Salmon I, Appelboom T, and Kiss R (1999). $\mathrm{D}-$ Mannose and $\mathrm{N}$-acetylglucosamine moieties and their respective binding sites in salivary glands of Sjögren's syndrome. J Rheumatol 26:833-841.

Terris J, Ecelbarger CA, Marples D, Knepper MA, and Nielsen $S$ (1995). Distribution of aquaporin-4 water channel expression within rat kidney. Am J Physiol 269:F775-F785.

Thomas E, Hay EM, Hajeer A, and Silman AJ (1998). Sjögren's syndrome: A community-based study of prevalence and impact. $\mathrm{Br} \mathrm{J}$ Rheumatol 37:1069-1076.

Tornwall J, Konttinen Y, Tuomen R, and Tornwall M (1997). Salivary gland acinar epithelial cells are deficient in their protein kinase C expression in Sjögren's syndrome. Lancet 349:1914-1915.

Vazquez JJ, Vazquez M, Idoate MA, Montuenga L, MartinezAnso E, Castillo JE, Garcia N, Medina JF, and Prieto J (1995). Anion exchanger immunoreactivity in human salivary glands in health and Sjögren's syndrome. Am J Pathol 146:14221432.

Verkman AS, Van Hoek AN, Ma T, Frigeri A, Skach WR, Mitra A, Tamarapoo BK, and Farinas J (1996). Water transport across mammalian cell membranes. Am J Physiol 270:C12С30.

Vissink A, Kalicharan D, s'Gravenmade EJ, Jongbloed WL, Ligeon EE, Nieuwenhuis P, and Konings WT (1991). Acute irradiation effects on morphology and function of rat submandibular glands. J Oral Pathol Med 20:449-456.

Vitali C, Bombardieri S, Moutsopoulos HM, Balestrieri G, Bencivelli W, Bernstein RM, Bjerrum KB, Braga S, Coll J, and de Vita $S$ (1993). Preliminary criteria for the classification of Sjögren's syndrome. Results of a prospective concerted action supported by the European Community. Arthritis Rheum 36:340-347. 